\title{
Feeding chicks exclusively via implanted plastic fistulas
}

\author{
Graham M. Sterritt and Maurice P. Smith \\ UNIVERSITY OF COLORADO MEDICAL CENTER
}

\begin{abstract}
Abstraet
Surgical introduction of a plastic tube into the crop permits remote injection of all fluids and nutrients, beginning before any normal feeding has occurred. Total alimentary intake can be controlled precisely, and hunger and thirst can be manipulated at will by this technique. Chicks raised by tube-feeding, never eating or drinking, appear to grow adequately.
\end{abstract}

The technique described below was devised to aid in studying various motivational and experiential factors in early psychological development. The eventual goals of this work are to explore with chicks such problems as the role of hunger and thirst needs in the development of activity cycles, exploratory behavior and generalized learning ability.

Essentially, the method of preparing chicks consists of fastening one end of a plastic tube inside the esophagus and passing the other end of the tube through the skin to the outside. Nutrients in semi-liquid form can then be injected directly into the crop through a light, flexible external tube attached to a syringe or pump outside the living cage.

In greater detail, the method is as follows. Leghorn chicks (Hy-Line 934) are obtained from a commercial hatchery within $24 \mathrm{hr}$. of hatching. A $100 \mathrm{~mm}$ section of PE 205 plastic tubing (Clay Adams) is heat flared to form a $4 \mathrm{~mm}$ flange at one end. Chicks are anesthetized, an incision is made in the neck and the tube is introduced surgically so that the flared end is just. cranial to the crop. The other end of the tube passes under the skin to the top of the head where approximately $25 \mathrm{~mm}$ projects out.

About $48 \mathrm{hr}$. after hatching, the implanted tube is attached to a heat formed spiral of the same material suspended overhead, connected to a pump or syringe.

Of a number of food and water formulas that have been tried, one has proved most successful for healthy maintenance over long periods of time. ${ }^{2}$

A variety of syringe pumps and finger and rotary tubing pumps have been used. None has proved dependable over long periods and it is necessary to monitor the pump or to use a hand operated syringe to move the mixture reliably.

Despite frequent pumping irregularities, including interruptions of feeding and occasional over-feeding, two chicks were maintained by pump feeding for 30 days, two for 51 days and one for 71 days. None ever consumed food or water by mouth before or during these periods.
However, those that survived the pump-feeding experiments were in every case underweight by the 10th day, while those that received enough to assure that they did not fall below controls in body weight always succumbed by the 10 th day. This raised the possibility that young chicks may not tolerate injections of quantities of food large enough to sustain normal growth.

To test this hypothesis, a group of 10 Ss was set up, tube-fed the diet ${ }^{2}$ approximately every 24 min., 18 hr. a day for 10 days, by hand syringe feeding. Amounts tube-fed were determined at each feeding according to the fullness of the crop. Nothing was tube-fed during the other $6 \mathrm{hr}$. and food and water were never offered to be consumed by mouth.

On the supposition that enviromental stimulation paired with tube-feeding might be important for optimal utilization of food injections, home cage doors were opened before every tube-feeding, a stimulus panel was introduced and a few pecks were elicied by pushing the chick's head against the panel during the tubefeeding.

One unoperated control group of 10 chicks was given granular C hick S tar ten a (Ralston Purina Co.) in conventional feeders, with separate waterers $18 \mathrm{hr}$. per day, with no access to food or water in the remaining $6 \mathrm{hr}$. The other unoperated control group of $10 \mathrm{Ss}$ had access to food and water $24 \mathrm{hr}$. per day.

The tube pulled out of one $S$ on the fourth day. Figure 1 reveals that the nine remaining hand syringe fed Ss gained more in body weight during the 10 day period, by comparison to either unoperated control group. All appeared healthy and vigorous throughout the experiment.

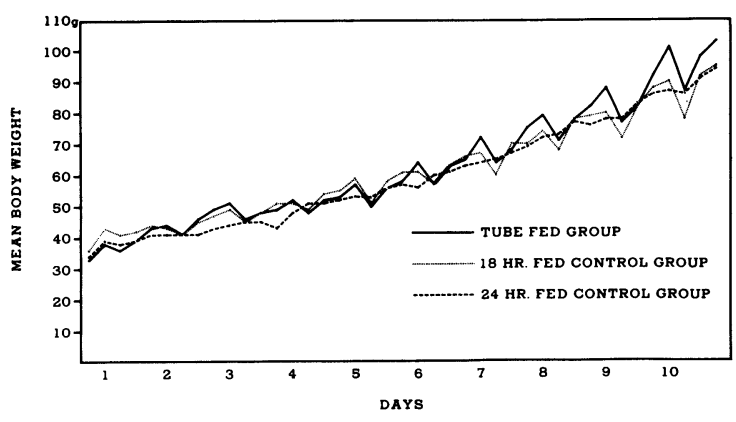

Fig. 1. Mean body weight of tube-fed Ss, $18 \mathrm{hr}$. fed controls and $24 \mathrm{hr}$. fed controls in the first study in which the syringe feeding method was employed. 
The excellent development of the hand syringe fed Ss indicated that the poor results with pump-fed birds were probably due to the very irregular delivery of food, which was the rule when the pumps were used. The main alternative explanation was that some special feature of the hand syringe feeding procedure is essential for adequate growth and development. Stimulation during tube-feeding and precise regulation of amounts tube-fed according to the fullness of the crop were both included in the hand syringe study but not in the pump studies.

In order to determine which of the procedures used in the hand syringe feeding study were essential, another hand syringe feeding study was carried out. This study employed 16 Ss divided evenly among four groups, all tube-fed $18 \mathrm{hr}$, per day. Four "no stimulus" Ss received the diet ${ }^{2}$ from a cooled reservoir, as before, but lived in closed boxes and received no environmental stimulation when tube-fed. Four "warm diet" Ss received the same diet kept at $35^{\circ} \mathrm{C}$., to determine the effects of some degree of spoilage of the diet. Four "milk diet" Ss received a milk-base diet which was of a less heavy consistency and moved more easily through the tubes. The milk diet was kept in a cooled reservoir and the Ss of this group received stimulation during tubefeeding. Finally, four "level dose" Ss were fed the diet from a cooled reservoir, with stimulation, but received the same amount at every feeding, regardless of the condition of the crop, over a $9 \mathrm{hr}$. period. The amount tube-fed this group was varied only at the start and again half way through the $18 \mathrm{hr}$. of tube-feeding each day.

One $\mathrm{S}$ in the milk-diet group died, apparently of a yolk sac infection resulting from an improper anesthetization procedure. Body weight gain among the other 15 tubefed Ss compared favorably with weight gains among the unoperated controls. Measurements of leg and wing length indicated that the tube-fed Ss equalled $24 \mathrm{hr}$. fed controls, while $18 \mathrm{hr}$ fed controls were exceeded by both of the other groups in body size. All four tube-fed subgroups gained at about the same rate.
Thus it appears likely that neither precise regulation of amounts tube-fed according to the momentary condition of the crop nor environmental stimulation at the time of tube-feeding is necessary for adequate growth. Spoiling the diet by warming it or including milk to make the diet thinnner in consistency also had no obvious ill effects.

After the 10th day the 15 surviving tube-fed Ss were disconnected from their tubes and set up as groups of four Ss with granular $\mathrm{C} \mathrm{hick} \mathrm{Starten} \mathrm{a} \mathrm{in} \mathrm{conventional}$ feeders and separate waterers. Subsequent body weight gain was the same as that of unoperated controls, after an initial drop to the level of the $24 \mathrm{hr}$. fed controls. The initial weight loss after the cessation of tube-feeding may be explained on the basis that tube-fed chicks were totally unpracticed in normal eating and drinking and required some time to learn these behaviors. Since the tubes were left in place after tube-feeding ended, it is obvious that tubes may be installed in a way that does not interfere with normal eating and drinking.

Chicks prepared in the manner described above have been employed in a series of studies designed to analyze the effects of internal stimulus components and consumatory stimulus components in the reinforcement effects associated with feeding (Sterritt \& Smith, 1965).

The method may be of more general utility, e.g., in physiological studies of nutrition and growth, in addition to its usefulness in behavioral research.

\section{References}

STERRITT, G. M., \& SMITH, M. P. Reinforcement effects of specific components of feeding in young leghorn chicks. J. comp. physiol. Psychol., 1965, in press. Notes

1. The first author is the recipient of a Research Career Development Award, given by the National Institute of Child Health and Human Development. This work was supported by two Public Health Service Research Grants (M-2633 A and M-3578) from the National Institute of Mental Health, and by a grant from the Fluid Research Fund, University of Colorado Medical Center. Arnold Hennig, Eldon Kienholz, Robert Moreng, Peter Shreck and Martin Steinberg made important contributions to the method.

2. $100 \mathrm{~g}$ Purina Chick Startena (Ralston Purina Co.) micromilled to approximately 80 mesh fineness, $250 \mathrm{ml}$ water, $1 \mathrm{ml} \mathrm{Paladac}$ (Park-Davis), $0.1 \mathrm{ml}$ Aqua Sol E (U.S. Vit.), $0.5 \mathrm{~g} \mathrm{Na}$ Benzoate. 